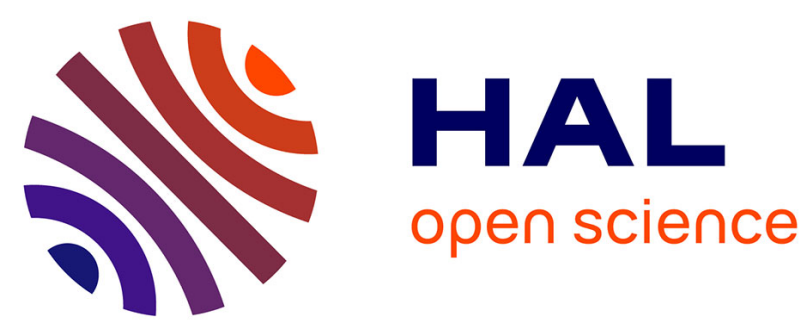

\title{
Developments of nano-polycrystalline diamond anvil cells for neutron diffraction experiments
}

Kazuki Komatsu, Stefan Klotz, Satoshi Nakano, Shinichi Machida, Takanori Hattori, Asami Sano-Furukawa, Keishiro Yamashita, Tetsuo Irifune

\section{- To cite this version:}

Kazuki Komatsu, Stefan Klotz, Satoshi Nakano, Shinichi Machida, Takanori Hattori, et al.. Developments of nano-polycrystalline diamond anvil cells for neutron diffraction experiments. High Pressure Research, 2020, 40 (1), pp.184-193. 10.1080/08957959.2020.1727465 . hal-02507351

\section{HAL Id: hal-02507351 https://hal.sorbonne-universite.fr/hal-02507351}

Submitted on 13 Mar 2020

HAL is a multi-disciplinary open access archive for the deposit and dissemination of scientific research documents, whether they are published or not. The documents may come from teaching and research institutions in France or abroad, or from public or private research centers.
L'archive ouverte pluridisciplinaire HAL, est destinée au dépôt et à la diffusion de documents scientifiques de niveau recherche, publiés ou non, émanant des établissements d'enseignement et de recherche français ou étrangers, des laboratoires publics ou privés. 
Published in: High Pressure Research 40, 184 (2020)

\section{Developments of nano-polycrystalline diamond anvil cells for neutron diffraction experiments}

Kazuki Komatsu蝶, Stefan Klotz ${ }^{\mathrm{b}}$, Satoshi Nakano ${ }^{\mathrm{c}}$, Shinichi Machida ${ }^{\mathrm{d}}$,

Takanori Hattori ${ }^{\mathrm{e}}$, Asami Sano-Furukawa ${ }^{\mathrm{e}}$, Keishiro Yamashita ${ }^{\mathrm{a}}$, Tetsuo Irifune $^{\mathrm{f}}$

${ }^{a}$ Geochemical Research Center, Graduate School of Science, The University of Tokyo,

7-3-1 Hongo, Bunkyo-ku, Tokyo 113-0033, Japan

${ }^{b} I M P M C$, UMR 7590, Sorbonne Université, 4 Place Jussieu, F-75252 Paris, France

${ }^{c}$ National Institute for Materials Science (NIMS), 1-1 Namiki, Tsukuba, Ibaraki 305-

0044, Japan

${ }^{d}$ CROSS, Neutron Science and Technology Center, 162-1 Shirakata, Tokai, Naka,

Ibaraki 319-1106, Japan

${ }^{e} J$-PARC Center, Japan Atomic Energy Agency, 2-4 Shirakata, Tokai, Naka, Ibaraki 319-1195, Japan

${ }^{f}$ Geodynamics Research Center, Ehime University, Matsuyama, Japan 


\title{
Developments of nano-polycrystalline diamond anvil cells for neutron diffraction experiments
}

\begin{abstract}
A new high-pressure cell for neutron diffraction experiments using nanopolycrystalline anvils is presented. The cell design, off-line pressure generation tests and a gas-loading procedure for this cell are described. The performance is illustrated by powder neutron diffraction patterns of ice VII to $\sim 82 \mathrm{GPa}$. We also demonstrate the feasibility of single crystal neutron diffraction experiments of $\mathrm{Fe}_{3} \mathrm{O}_{4}$ at ambient conditions using this cell and discuss the current limitation and future developments.
\end{abstract}

Keywords: neutron diffraction; nano-polycrystalline diamond; high pressure

\section{Introduction}

Recent studies on high- $T_{\mathrm{c}}$ superconducting materials have attracted considerable interest as hydrogen sulphide $\left(\mathrm{H}_{3} \mathrm{~S}[1]\right)$ shows $T_{\mathrm{c}}=203 \mathrm{~K}[2]$, and more recently $T_{\mathrm{c}} \sim 250$ $\mathrm{K}$ was reported for lanthanum hydride $\left(\mathrm{LaH}_{3}\right)$ [3, 4]. Such high- $T_{\mathrm{c}}$ is achieved only under Mbar pressures and all of these high- $T_{\mathrm{c}}$ materials contain hydrogens in their structure. However, in none of these systems, the hydrogen positions have ever been confirmed experimentally. Even for more moderate pressure ranges, hydrogen positions are of fundamental interests and play key roles in physical properties of high-pressure ices [5], metal hydrides [6], hydrous minerals [7] etc. Neutron diffraction experiments under such extreme conditions would, therefore, be highly desirable.

Neutron diffraction requires significantly larger sample volumes than x-ray diffraction because of the weak flux of available neutron sources. For this reason, crystallographic studies by neutron diffraction have long been limited to $30 \mathrm{GPa}$ using the Paris-Edinburgh press [8]. The Paris-Edinburgh press with toroidal anvil profiles enables to load larger samples than conventional diamond anvil cells (DACs) and thereby enables accurate structure refinements [9]. Recent progress in the anvil design allowed to increase the current limit to $40 \mathrm{GPa}$ by reducing the diameter of top of the sintered diamond anvils from $4.0 \mathrm{~mm}$ to $1.0 \mathrm{~mm}$ [10], but the attainable maximum pressure is still far below one Mbar. On the other hand, a conically supported single crystal DAC enables neutron diffraction experiments at pressures as high as 94 GPa several years ago [11], 
and more recently the data with refinable quality are obtained up to $60 \mathrm{GPa}$ [5]. These record still remains up to date.

Because of its hardness, toughness and the absence of cleavage planes, nanopolycrystalline diamond (NPD) $[12,13,14]$ would be a promising material to overcome the current limitation of pressure generation. It was demonstrated that the achievable pressure with nano-polycrystalline DAC (NPDAC) is about 1.5 to 2 times higher than that of single-crystal DACs when anvils with a culet size of more than $300 \mu \mathrm{m}$ are used [15]. NPD has also an advantage for correcting diffraction intensities because the attenuation by the anvils is independent of the orientation of the crystal. Single crystal diamonds have, on the contrary, a complicated angle and wavelength dependence for attenuation corrections [16].

Although NPD anvils were already used for neutron diffraction experiments up to $14 \mathrm{GPa}$ for a sample with a volume of $0.7 \mathrm{~mm}^{3}$ [17], no further studies under higher pressures have been conducted up to date. Here we show a new cell design for neutron diffraction experiments using the NPD anvils, and results of off-line pressure generation tests, gas-loading into such a cell as well as preliminary neutron diffraction experiments.

\section{Cell design and gasket}

The NPDAC presented here (Fig. 1) consists mainly of a cylindrical body, pistons made of hardened steel, two NPD anvils, and tungsten carbide (WC) seats. The design is based on a previously developed sapphire clamp cell for high-pressure viscosity measurements [18]. The NPD anvils were provided from Geodynamics Research Center, Ehime University, Japan, and the currently available size is up to $10 \mathrm{~mm}$ in both height and diameter. The NPD anvils used in this study have $6 \mathrm{~mm}$ height and are $6 \mathrm{~mm}$ in diameter with a $1.5^{\circ}$ lateral taper to insert them into steel supporting rings. The reason for this 'flat' base design instead of the previously applied conically tapered support [11] is the easier alignment of anvil culets being parallel. The translation and orientation of the NPD anvils are mechanically defined with no further manual alignment being necessary. This is not so straightforward in the case of conically tapered anvils. On the other hand, a large diameter of anvils is necessary for the seats to support the high load, which is incompatible with single crystal diamond in terms of the cost. The culet size in this study is $1.0 \mathrm{~mm}$ and NPD anvils with a single bevel ( $8^{\circ}$ in the region within $1.5 \mathrm{~mm}$ or $2.5 \mathrm{~mm}$ 
diameter). The cell has - apart from a tightening mechanism using several bolts on the top cap - no load generation mechanism and could hence be classified as "a clamp module". The forces of up to 10 tons (due to the large culet size) for generating pressures in the GPa range and higher has to be provided by an additional ram. In our case, we use a VX2 Paris Edinburgh press (120 mm diameter, $8 \mathrm{~kg}$ mass, 50 tons capacity) which is perfectly adapted to the NPDAC allowing remote controlled pressure changes. The opening aperture angle of this cell is limited up to approx. $\pm 15 \mathrm{deg}$. from the vertical plane to the compression axis, and $140 \mathrm{deg} . \times 2$ in the holizontal plane limited due to the pillars of the clamp.

High-strength SUS301 grade stainless steel (Sumitomo Metal Industries, Ltd. or Nippon Kinzoku co. Ltd.) was used as gasket material as previously reported [11]. Starting from an initial thickness of $200-260 \mu \mathrm{m}$. The gaskets were pre-indented to 80 $-120 \mu \mathrm{m}$ by a force of $1.0-1.6$ ton, and the initial diameter of the sample hole was 300 $-500 \mu \mathrm{m}$ for off-line test. The NPD anvil and gasket geometry for neutron diffraction experiments are described in the following section.

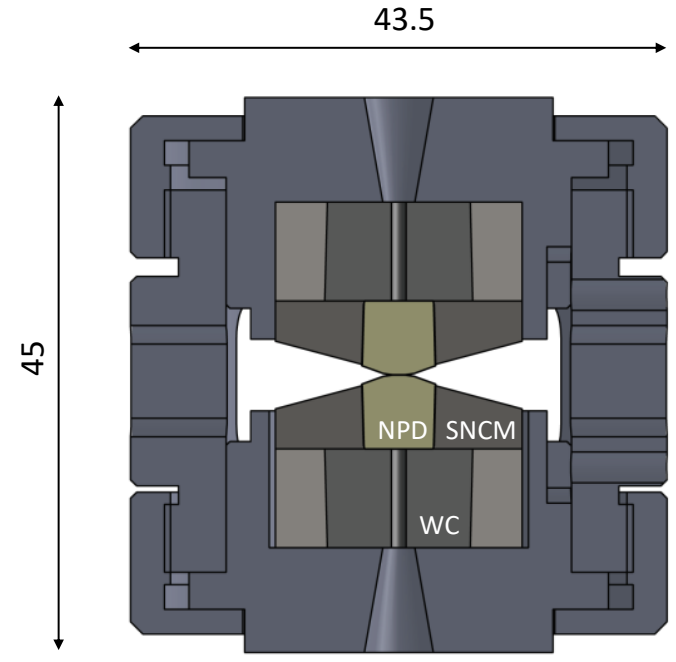

(a)

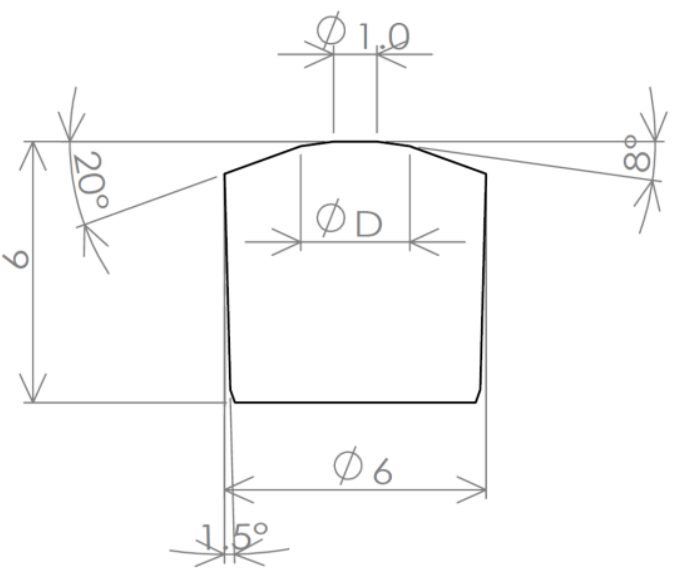

(b)

Figure 1. Drawings of a newly designed NPDAC (left) and the enlarged view of NPD anvil (right). The NPD anvil has a bevel of $8^{\circ}$ in the region within $D \mathrm{~mm}$ in diameter. SNCM means the support ring made of hardened steel (SNCM439), and WC means the tungsten carbide seat. 


\section{Experiments}

\section{Gas loading}

The cell is small enough to be compatible with gas-loading systems used for conventional diamond anvil cells [19]. Loading of helium gas, the most commonly used pressure transmitting medium, was tested in this study at NIMS [19] and IMPMC [20]. For this purpose, the NPDAC was inserted into a loading frame that can apply and hold the force on the anvils by a screw-type mechanism. This assembly was then introduced into a high-pressure vessel similar to the procedure applied for conventional DACs [19]. The vessel was loaded with He gas of up to $180 \mathrm{MPa}$ and the cell clamped by rotating the screw on the loading frame with a shaft through the breach of the vessel. After releasing the gas pressure and removing the cell from the vessel, four M4 screws on the cap of the NPDAC are tightened as much as possible in order to hold the load applied to the anvils. After this manoeuvre, the force on the loading clamp can be released and the NPDAC be taken off. The measured sample pressure was found to be ca. $0.3 \mathrm{GPa}$. The success rate of He loadings was over $90 \%$.

\section{Neutron diffraction}

Neutron diffraction experiments were performed at the PLANET beamline [21] at the Materials and Life Science Experimental Facility (MLF) of J-PARC, Ibaraki, Japan. The incident beam consists of $25 \mathrm{~Hz}$ pulsed spallation neutrons, and the accelerator power was approximately $500 \mathrm{~kW}$ during the experiments. The experimental setup is the same as described in Ref.[6]. A focusing guide consisting of 1.0-m-long parabolic supermirrors with critical angles of $4.0 Q_{\mathrm{c}}\left(Q_{\mathrm{c}}\right.$ is the critical momentum transfer for $\left.\mathrm{Ni}\right)$, was placed in front of NPDAC to increase the neutron flux at the sample position. The cell was oriented with the thrust axis parallel to the incident neutron beam $(\lambda=0.28-5.97 \AA)$. The scattered neutrons were detected using position-sensitive ${ }^{3} \mathrm{He}$ gas detectors positioned in a pair of banks at $2 \theta=90$ degrees (coverage: $2 \theta=90 \pm 11.3^{\circ}, \chi=0 \pm 34.6^{\circ}[21]$ ). To reduce the background, radial collimators with a gauge length of $1.5 \mathrm{~mm} \mathrm{[21]} \mathrm{were} \mathrm{installed} \mathrm{between}$ the sample and detectors. Cylinders made of hBN were inserted in the upperstream side of the holes of the NPDAC for collimation of the incident beam, and a Cd foil (thickness $0.1 \mathrm{~mm}$ ) was glued onto the surface of the support ring (SNCM in Fig. 1) binding NPD anvils in order to minimize the unwanted scattering from the surrounding part. 
We loaded $\mathrm{D}_{2} \mathrm{O}$ as a sample for a neutron diffraction experiment. This system is well suited because the liquid sample fills the entire sample space and ice VII is a strong neutron scatterer. Two different anvil profiles were adopted for these measurements: One with flat anvil culets as used in the off-line test, and the other with cupped anvil culets to increase the sample volume. For both type of anvils, the diameter of the bevel $(\phi \mathrm{D}$, see Fig. 1 for geometry) of the NPD anvil was $2.5 \mathrm{~mm}$ and the culet diameter is $\phi 1.0 \mathrm{~mm}$. The radius of the cup was $500 \mu \mathrm{m}$ and the diameter of the edge of the cup on the culet was $\phi 1.0 \mathrm{~mm}$, resulting in a depth of the cup from the culet face is $100 \mu \mathrm{m}$. The gasket material for these neutron diffraction experiments was SUS301. The initial thickness of the gasket was $260 \mu \mathrm{m}$, preindented to $135 \mu \mathrm{m}$ for the run with flat anvils and to $207 \mu \mathrm{m}$ for the run with the cupped anvil. The diameter of the gasket hole was $400 \mu \mathrm{m}$ in both runs.

\section{Results and discussion}

\section{Off-line pressure generation test}

In order to test the feasibility of the NPDAC as a high-pressure neutron cell, we conducted off-line pressure generation tests as listed in Table 1. For these tests, NPD anvils with bevels $\phi \mathrm{D}=1.5 \mathrm{~mm}$ or $2.5 \mathrm{~mm}$ were used. $\mathrm{NaCl}, \mathrm{H}_{2} \mathrm{O}$, and helium with small ruby chips were inserted into the sample chamber. The pressure in the sample chamber was measured by the Ruby fluorescence method [22]. The NPDAC was inserted into the VX2-type PE press and the load onto the anvils (or assembly) was applied and controlled using helium gas as hydraulic fluid. The highest pressure achieved was $30.9 \mathrm{GPa}$ in Run 4 for the $\mathrm{H}_{2} \mathrm{O}$ sample. This was not the limit of the NPDAC but due to the limit of the pressure in the He-gas cylinder (14 MPa). Other runs using $\mathrm{NaCl}$ as a sample suffered from the problem that the sample hole expanded too much when the initial diameter of the sample hole was $500 \mu \mathrm{m}$, regardless of the gasket thickness. For $300 \mu \mathrm{m}$ (Run 7), the expansion was significantly reduced (Fig. 2) at the expense of sample volume.

After the release of pressure in Run 7, a ring crack was observed on the upper surface of the NPD anvils. This might be due to the large pressure gradient on the culet of the anvils. The generation and propagation of the ring crack were reduced when the diameter of the bevel region was extended from $1.5 \mathrm{~mm}$ to $2.5 \mathrm{~mm}$, as shown in Run 8 and the run for the diffraction experiments (see next section). 
In Run 8 in which helium was loaded as the sample, the pressure could not be increased to beyond $14 \mathrm{GPa}$. The anvil recovered in this run had a crack along the compression axis, which is typically observed when helium penetrates into the diamonds.

Table 1. Experimental conditions in off-line pressure generation tests of the NPDAC.

\begin{tabular}{|c|c|c|c|c|c|}
\hline Run\# & Sample & Gasket material $^{*}$ & $\begin{array}{l}\text { Gasket } \\
\text { thickness }(\mu \mathrm{m})^{* *}\end{array}$ & $\begin{array}{l}\text { Initial diameter of } \\
\text { sample hole }(\mu \mathrm{m})\end{array}$ & $\begin{array}{l}\text { Diameter of bevel } \\
(\phi \mathrm{D}, \mathrm{mm})^{* * *}\end{array}$ \\
\hline 1 & $\mathrm{NaCl}$ & SUS301 (SMI) & $200>123$ & 500 & 1.5 \\
\hline 2 & $\mathrm{NaCl}$ & SUS301 (SMI) & $200>123$ & 500 & 1.5 \\
\hline 3 & $\mathrm{NaCl}$ & SUS301 (SMI) & $200>82$ & 500 & 1.5 \\
\hline 4 & $\mathrm{H}_{2} \mathrm{O}$ & SUS301 (SMI) & $200>80$ & 500 & 1.5 \\
\hline 5 & $\mathrm{NaCl}$ & SUS301 (SMI) & $200>72$ & 500 & 1.5 \\
\hline 6 & $\mathrm{NaCl}$ & SUS301 (NK) & $260>83$ & 500 & 1.5 \\
\hline 7 & $\mathrm{NaCl}$ & SUS301 (NK) & $260>83$ & 300 & 1.5 \\
\hline 8 & $\mathrm{He}$ & SUS301 (NK) & $260>170$ & 400 & 2.5 \\
\hline
\end{tabular}

*SMI: Sumitomo Metal Industries, Itd., HV456, NK: Nippon Kinzoku co. Itd., HV527

(HV : Vickers hardness)

${ }^{* *}$ Values show gasket thickness like 'before $>$ after' pre-indentation

${ }^{* * *}$ See Fig. 1.

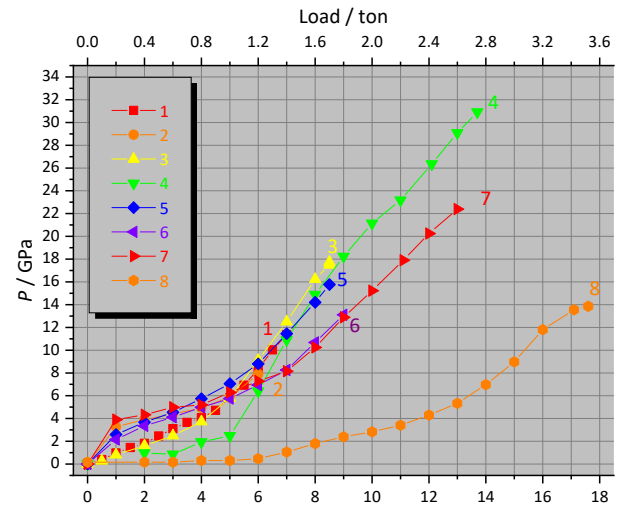

(a)

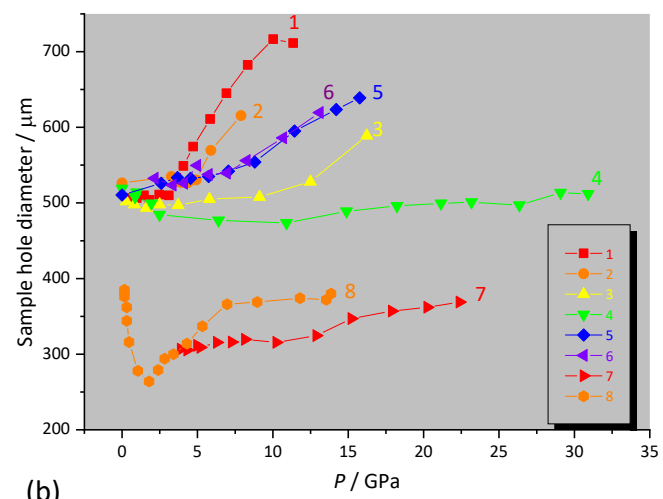

(b)

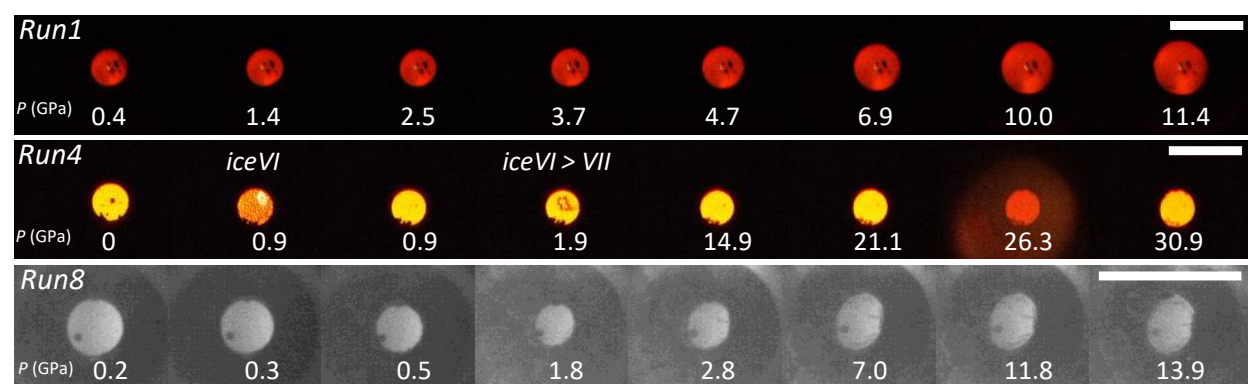

(c)

Figure 2. Results of off-line pressure generation tests. (a) Load-pressure curve, (b) the diameter of sample hole as a function of pressure, and (c) photos of sample chambers for Run1, Run4, and Run8. Experimental conditions for respective runs are shown in Table 1. White bars in (c) depict scales of $1.0 \mathrm{~mm}$. 


\section{Powder neutron diffraction on ice VII to $\sim 82$ GPa}

Powder neutron diffraction patterns of ice VII are shown in Figure 3(a) and 3(b), and details of experimental conditions with refined lattice parameters and estimated pressures are shown in Table 2. The sample pressures were estimated from the equation of state (EoS) of ice VII (see Table 2). As the strongest 110 peak of ice VII overlapped with a diamond reflection at pressures from $30 \mathrm{GPa}$ to $60 \mathrm{GPa}$, only one $d$-spacing of 111 was used to estimate pressure. The achieved pressure is $\sim 82 \mathrm{GPa}$ and $\sim 42 \mathrm{GPa}$ in the runs using the flat and cupped anvils, respectively (Fig. 3(c) and Table 2). In the run using the flat anvil, the load slightly dropped at the highest pressure and the recovered anvils (both sides) were seriously damaged. In the run using the cupped anvils the load was stable at the highest pressure, but one of the recovered anvils had radial cracks, whereas the other anvil had only a few ring cracks wihout any serious damage on the culet. In the run using cupped anvils, the thinnest part of the recovered gasket was less than $10 \mu \mathrm{m}$ thick. It is likely that the curvature change at around $35 \mathrm{GPa}$ in the run using the cupped anvils was not due to the limit of the anvils but due to the 'dead volume' of the cup. Therefore, it should be worthwhile to pursue the cupped anvil design, for example, to optimize the geometry of cup and gasket, since peak intensities of ice VII using the cupped anvils are approx. 5 times larger and those from NPD are approx. 2/3rd compared to those using the flat anvils (Fig. 3(d)). The diffraction patterns have refinable quality, particulary for the data taken using the cupped anvil. Details of the structure analysis for ice VII will be reported elsewhere. 


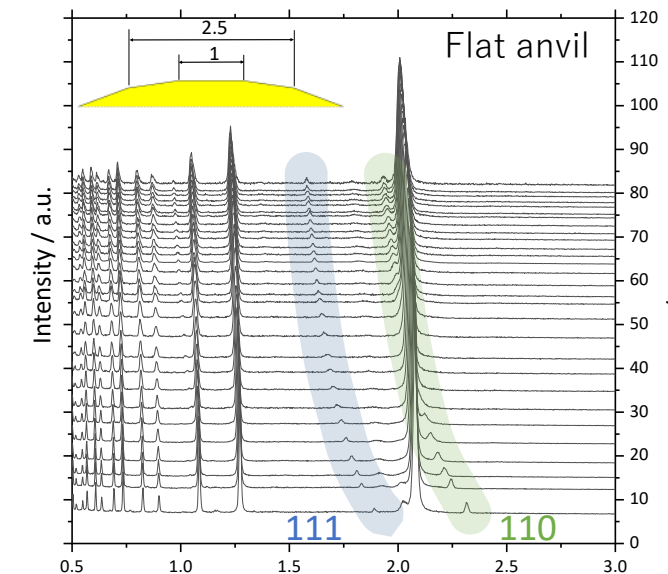

(a)

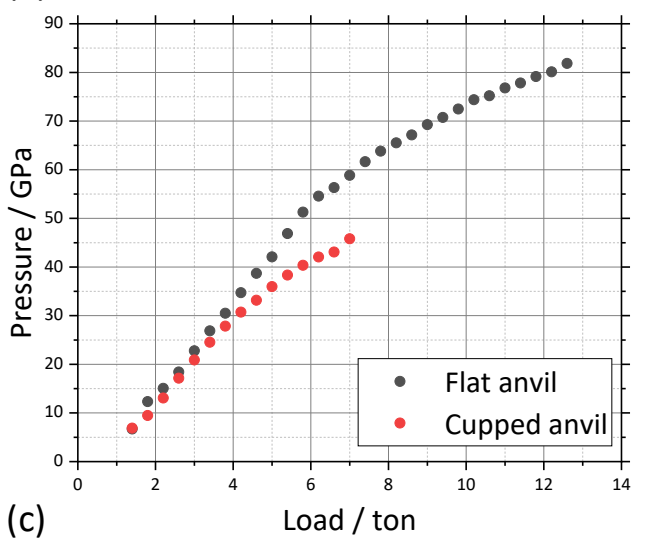

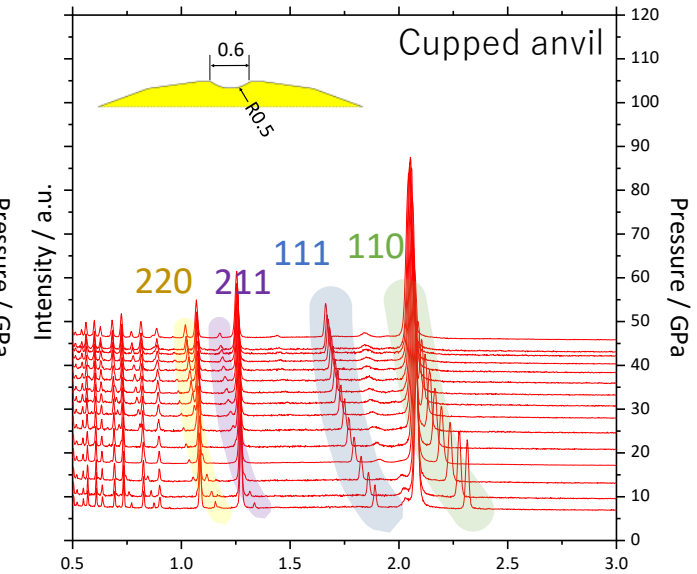

(b)

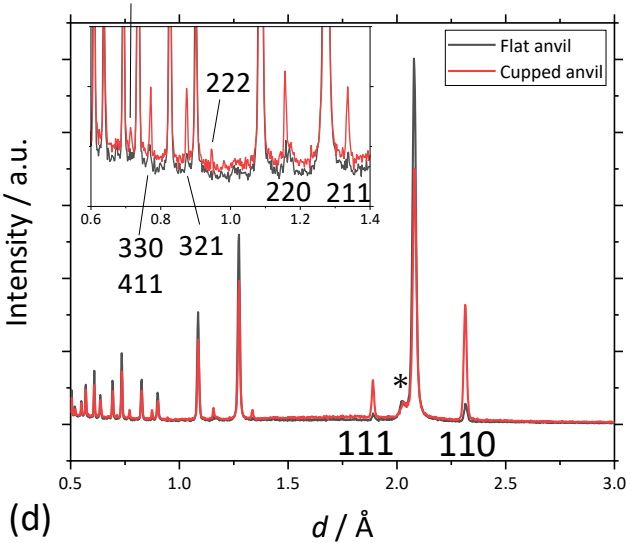

Figure 3. Powder neutron diffraction patterns of ice VII obtained with the NPDAC using (a) flat anvil and (b) cupped anvil. (c) Pressure vs. load curves for the flat and cupped anvils. (d) Comparison of neutron diffraction patterns taken at around $6 \mathrm{GPa}$ using the flat and cupped anvils. Geometries of the flat and cupped anvils are shown as insets in (a) and (b), respectively. The corresponding experimental numbers are \#59833 and \#59666 for the flat and cupped anvils, respectively (see Table 2). Diffraction intensities in (a), (b) and (d) are scaled by proton numbers (proportional to the total flux of incident beam), but not corrected for wavelength-dependent factors, such as the energy profile of incident beam, detector efficiency, attenuation, etc. Background subtraction was not applied. Diffraction patterns in (a) and (b) are shifted such that they cross the right hand vertical axis at their measurement pressure. The pressures shown in (a), (b), and (c) are estimated from the equation of state of ice VII reported by Hemley et al. [23] Exposure time for each measurement is 60 - $90 \mathrm{~min}$. for almost all measurements (see more details in Table 2). An inset in (d) shows enlarged diffraction patterns in the low- $d$ region. Indices in (a), (b) and (d) show the Bragg peaks of ice VII, and an asterisk in (d) shows the strongest 110 peak of $\alpha-F e$ (gasket) and other unindexed peaks are from NPD anvils. 
Table 2. Experimental conditions, lattice parameters and the measurement pressures for powder neutron diffraction experiments. The pressures are estimated using a third-order Birch equation ("Birch-Murnaghan" EoS, abbreviated as "BM") of ice VII reported in Hemley et al.[23] and Wolanin et al.[24], and using a Rydberg-Vinet EoS (also called "Vinet" EoS, abbreviated as "RV") reported in Somayazulu et al.[25]

\begin{tabular}{|c|c|c|c|c|c|c|c|}
\hline \multirow[b]{2}{*}{ Exp.\# } & \multirow{2}{*}{$\begin{array}{r}\text { Load } \\
\text { (ton) }\end{array}$} & \multirow{2}{*}{$\begin{array}{l}a \\
(\AA)\end{array}$} & \multirow{2}{*}{$\begin{array}{l}V \\
\left(\AA^{3}\right)\end{array}$} & \multicolumn{3}{|c|}{$P(\mathrm{GPa})$} & \multirow{2}{*}{$\begin{array}{c}\text { Exposure time } \\
(\min .)\end{array}$} \\
\hline & & & & Hemley (BM) & Wolanin (BM) & Somayazulu (RV) & \\
\hline \multicolumn{8}{|l|}{ Flat anvil } \\
\hline 59833 & 1.4 & 3.234 & 33.82 & 6.70 & 4.92 & 5.54 & 96 \\
\hline 59834 & 1.8 & 3.132 & 30.72 & 12.3 & 9.52 & 9.82 & 65 \\
\hline 59835 & 2.2 & 3.093 & 29.60 & 15.1 & 11.9 & 12.1 & 65 \\
\hline 59836 & 2.6 & 3.052 & 28.44 & 18.4 & 14.8 & 14.9 & 65 \\
\hline 59837 & 3.0 & 3.007 & 27.18 & 22.8 & 18.8 & 18.8 & 65 \\
\hline 59838 & 3.4 & 2.970 & 26.19 & 26.9 & 22.7 & 22.7 & 57 \\
\hline 59847 & 3.8 & 2.941 & 25.43 & 30.5 & 26.2 & 26.1 & 65 \\
\hline 59848 & 4.2 & 2.910 & 24.65 & 34.7 & 30.4 & 30.3 & 65 \\
\hline 59849 & 4.6 & 2.884 & 24.00 & 38.7 & 34.4 & 34.4 & 65 \\
\hline 59850 & 5.0 & 2.864 & 23.49 & 42.1 & 37.8 & 37.9 & 65 \\
\hline 59851 & 5.4 & 2.838 & 22.85 & 46.9 & 42.8 & 42.9 & 65 \\
\hline 59852 & 5.8 & 2.815 & 22.32 & 51.3 & 47.5 & 47.7 & 65 \\
\hline 59853 & 6.2 & 2.800 & 21.95 & 54.6 & 51.0 & 51.3 & 65 \\
\hline 59854 & 6.6 & 2.792 & 21.76 & 56.3 & 52.9 & 53.3 & 65 \\
\hline 59863 & 7.0 & 2.781 & 21.51 & 58.8 & 55.6 & 56.1 & 65 \\
\hline 59864 & 7.4 & 2.769 & 21.24 & 61.6 & 58.7 & 59.2 & 65 \\
\hline 59866 & 7.8 & 2.761 & 21.04 & 63.8 & 61.1 & 61.7 & 373 \\
\hline 59867 & 8.2 & 2.754 & 20.88 & 65.5 & 63.0 & 63.6 & 65 \\
\hline 59868 & 8.6 & 2.748 & 20.74 & 67.1 & 64.8 & 65.5 & 65 \\
\hline 59869 & 9.0 & 2.740 & 20.57 & 69.3 & 67.2 & 67.9 & 65 \\
\hline 59870 & 9.4 & 2.734 & 20.45 & 70.7 & 68.8 & 69.6 & 65 \\
\hline 59871 & 9.8 & 2.728 & 20.31 & 72.5 & 70.8 & 71.6 & 65 \\
\hline 59880 & 10.2 & 2.722 & 20.16 & 74.4 & 73.0 & 73.9 & 65 \\
\hline 59881 & 10.6 & 2.719 & 20.10 & 75.2 & 73.9 & 74.8 & 65 \\
\hline 59882 & 11.0 & 2.713 & 19.98 & 76.8 & 75.7 & 76.7 & 65 \\
\hline 59883 & 11.4 & 2.710 & 19.90 & 77.8 & 76.9 & 77.9 & 65 \\
\hline 59884 & 11.8 & 2.706 & 19.81 & 79.1 & 78.4 & 79.5 & 65 \\
\hline 59885 & 12.2 & 2.703 & 19.74 & 80.1 & 79.5 & 80.6 & 65 \\
\hline 59887 & 12.6 & 2.697 & 19.62 & 81.9 & 81.5 & 82.7 & 20 \\
\hline \multicolumn{8}{|c|}{ Cupped anvil } \\
\hline 59666 & 1.4 & 3.230 & 33.69 & 6.89 & 5.07 & 5.68 & 97 \\
\hline 59667 & 1.8 & 3.179 & 32.12 & 9.48 & 7.15 & 7.59 & 63 \\
\hline 59679 & 2.2 & 3.121 & 30.40 & 13.1 & 10.2 & 10.4 & 79 \\
\hline 59686 & 2.6 & 3.067 & 28.85 & 17.1 & 13.7 & 13.8 & 552 \\
\hline 59688 & 3.0 & 3.025 & 27.69 & 20.9 & 17.1 & 17.1 & 60 \\
\hline 59689 & 3.4 & 2.990 & 26.74 & 24.5 & 20.5 & 20.5 & 56 \\
\hline 59690 & 3.8 & 2.962 & 25.98 & 27.8 & 23.6 & 23.6 & 97 \\
\hline 59691 & 4.2 & 2.939 & 25.38 & 30.7 & 26.4 & 26.4 & 65 \\
\hline 59698 & 4.6 & 2.921 & 24.92 & 33.2 & 28.8 & 28.8 & 89 \\
\hline 59699 & 5.0 & 2.902 & 24.43 & 36.0 & 31.6 & 31.6 & 58 \\
\hline 59700 & 5.4 & 2.887 & 24.05 & 38.3 & 34.0 & 34.0 & 58 \\
\hline 59701 & 5.8 & 2.874 & 23.74 & 40.4 & 36.1 & 36.1 & 103 \\
\hline 59702 & 6.2 & 2.864 & 23.49 & 42.1 & 37.8 & 37.9 & 55 \\
\hline 59703 & 6.6 & 2.858 & 23.35 & 43.1 & 38.9 & 38.9 & 63 \\
\hline 59704 & 7.0 & 2.843 & 22.99 & 45.8 & 41.7 & 41.8 & 300 \\
\hline
\end{tabular}




\section{Single crystal neutron diffraction for $\mathrm{Fe}_{3} \mathrm{O}_{4}$}

Bragg spots from a single crystal are generally much stronger than the Debye rings from a powder sample when comparing them in the limited solid angle around Bragg spots. We demonstrate here that single crystal neutron diffraction is possible for a very small sample of $\mathrm{Fe}_{3} \mathrm{O}_{4}$ (magnetite). Figure 4 shows a neutron diffraction pattern from a thin piece of $\mathrm{Fe}_{3} \mathrm{O}_{4}$ with a size of $0.20 \mathrm{~mm} \times 0.15 \mathrm{~mm} \times 0.08 \mathrm{~mm}$, cut parallel to (110) and set on the culet of the NPD anvil. Incident neutron beam travels along the compression axis of the NPDAC, the $h 00$ Bragg spots were observed at $2 \theta=90^{\circ}$. When we integrate the diffraction intensity only around the $h 00$ spots in the two-dimensional diffraction pattern, the sample signal was dominant compared to the Debye ring from the NPD anvil, even though the NPD anvil had a much larger volume than the sample (Fig. $4)$.

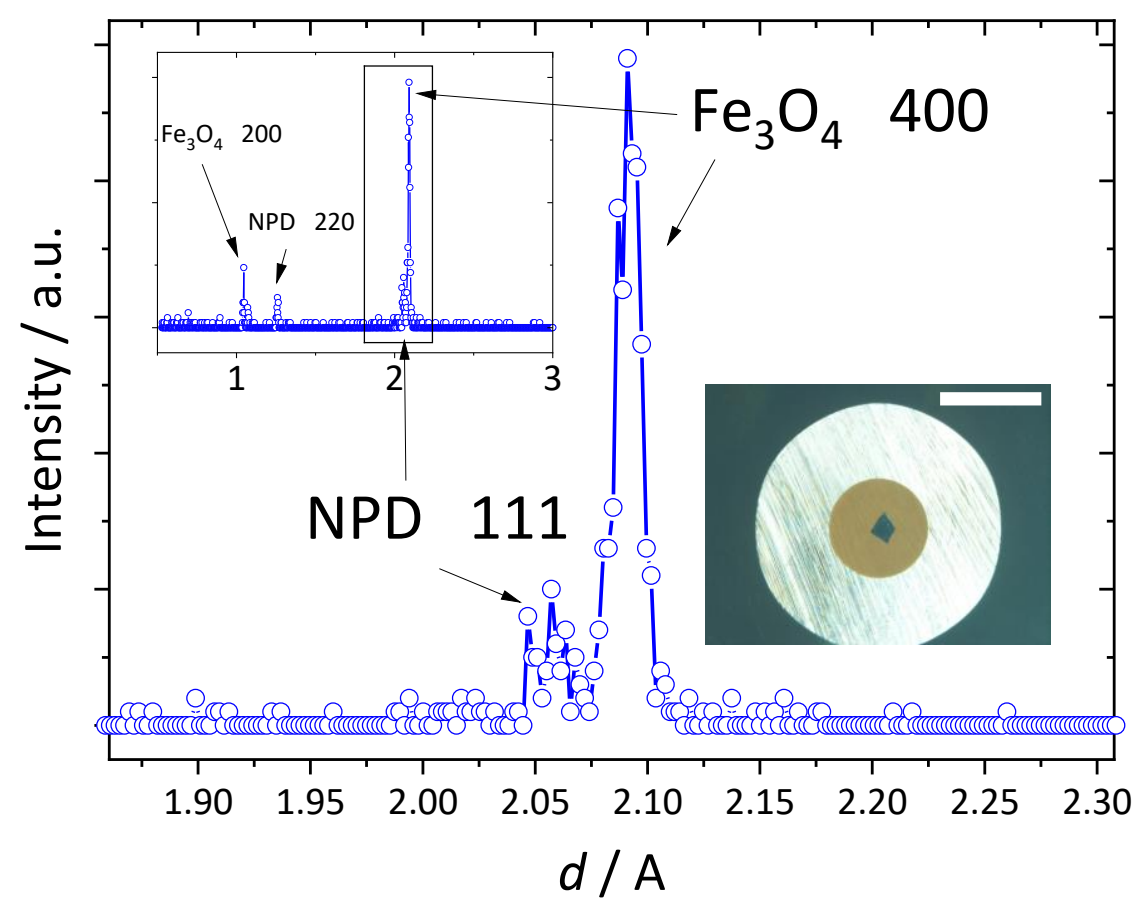

Figure 4. Neutron diffraction pattern from a thin piece of single crystal $\mathrm{Fe}_{3} \mathrm{O}_{4}$ (magnetite) at ambient conditions. The thin piece was cut parallel to (110), and the size of the crystal was $0.20 \times 0.15 \times 0.08 \mathrm{~mm}$. The exposure time was $75 \mathrm{~min}$. A photo of the single crystal on the culet of the NPD anvil is shown in the inset. A white bar depicts a scale of $1.0 \mathrm{~mm}$. 


\section{Conclusion and outlook}

We demonstrated the potential of a newly developed NPDAC by off-line pressure generation, powder and single-crystal neutron diffraction. The highest pressure achieved up to now is $\sim 82 \mathrm{GPa}$ for an ice VII sample. A series of off-line experiments suggests that the gasket material and its sample chamber size should be optimized in order to reduce the gasket hole expansion for experiments on samples that are less compressible than ice VII, such as most inorganic crystals. The strong reflections from the NPD anvils are also problematic in powder neutron diffraction on systems with relatively small unit cells. For the study of magnetic structures, on the contrary, where most magnetic reflections are at large $d$-spacings, the contamination of the diffraction patterns by NPD would be less a problem. It also may be worth considering the 'through gasket' scattering geometry for future developments, i.e. the incident neutron beam perpendicular to the compression axis to avoid the scattering from the NPD anvils. A more serious problem for pressurizing above $10 \mathrm{GPa}$ will be pressure transmitting media as indicated in [10] because helium gas loading has been unsuccessful in this study due to probable helium penetration into the NPD anvil. On the other hand, the single crystal method should be a promising way to achieve pressures above $100 \mathrm{GPa}$, as exemplified by the small sample size tested in this study. The simple attenuation correction for NPD anvils will allow precise structure analyses from single crystal neutron diffraction experiments as discussed in [26]. 


\section{Acknowledgments}

We are grateful to Drs. J. Abe and K. Funakoshi for their assistance to the experiments, and Dr. H. Arima for giving information on the focusing mirror. Y. Guarnelli and A. Polian for help in the gas loading at IMPMC and J. Philippe for help in the design of the original sapphire cell. Neutron diffraction experiments were performed through the J-PARC user programs (Nos. 2016I0011, 2017I0011, 2019I0011, 2019B0119). This study was supported by JSPS KAKENHI (Grant Numbers: 18H05224, 18H01936, 15H05829) and JSPS-CNRS bilateral joint research project. 


\section{References:}

1. Einaga M, Sakata M, Ishikawa T, Shimizu K, Eremets MI, Drozdov AP, Troyan IA, Hirao N, Ohishi Y. Crystal structure of the superconducting phase of sulfur hydride. Nature Physics. 2016;12:835.

2. Drozdov AP, Eremets MI, Troyan IA, Ksenofontov V, Shylin SI. Conventional superconductivity at 203 kelvin at high pressures in the sulfur hydride system. Nature. 2015;525:73.

3. Drozdov AP, Kong PP, Minkov VS, Besedin SP, Kuzovnikov MA, Mozaffari S, Balicas L, Balakirev FF, Graf DE, Prakapenka VB, Greenberg E, Knyazev DA, Tkacz M, Eremets MI. Superconductivity at $250 \mathrm{~K}$ in lanthanum hydride under high pressures. Nature. 2019;569:528-31.

4. Somayazulu M, Ahart M, Mishra AK, Geballe ZM, Baldini M, Meng Y, Struzhkin VV, Hemley RJ. Evidence for Superconductivity above $260 \mathrm{~K}$ in Lanthanum Superhydride at Megabar Pressures. Phys Rev Lett. 2019;122:027001.

5. Guthrie M, Boehler R, Molaison JJ, Haberl B, dos Santos AM, Tulk C. Structure and disorder in ice VII on the approach to hydrogen-bond symmetrization. Phys Rev B.

2019;99:184112.

6. Machida A, Saitoh H, Hattori T, Sano-Furukawa A, Funakoshi K-i, Sato T, Orimo S-i, Aoki K. Hexagonal Close-packed Iron Hydride behind the Conventional Phase Diagram. Scientific Reports. 2019;9:12290.

7. Sano-Furukawa A, Hattori T, Komatsu K, Kagi H, Nagai T, Molaison JJ, dos Santos AM, Tulk CA. Direct observation of symmetrization of hydrogen bond in $\delta$-AlOOH under mantle conditions using neutron diffraction. Scientific Reports. 2018;8:15520.

8. Klotz S. Techniques in High Pressure Neutron Scattering: CRC Press, Taylor \& Francis Group; 2012.

9. Klotz S, Casula M, Komatsu K, Machida S, Hattori T. High-pressure structure and electronic properties of $\mathrm{YbD}_{2}$ to 34 GPa. Phys Rev B. 2019;100:020101.

10. Hattori T, Sano-Furukawa A, Machida S, Abe J, Funakoshi K, Arima H, Okazaki N. Development of a technique for high pressure neutron diffraction at $40 \mathrm{GPa}$ with a ParisEdinburgh press. High Press Res. 2019:1-9.

11. Boehler R, Guthrie M, Molaison JJ, dos Santos AM, Sinogeikin S, Machida S, Pradhan N, Tulk CA. Large-volume diamond cells for neutron diffraction above $90 \mathrm{GPa}$. High Press Res. 2013;33:546-54.

12. Irifune T, Kurio A, Sakamoto S, Inoue T, Sumiya H. Ultrahard polycrystalline diamond from graphite. Nature. 2003;421:599-600.

13. Sumiya H, Harano K. Distinctive mechanical properties of nano-polycrystalline diamond synthesized by direct conversion sintering under HPHT. Diamond Relat Mater. 2012;24:44-8.

14. Sumiya H, Irifune T. Hardness and deformation microstructures of nano-polycrystalline diamonds synthesized from various carbons under high pressure and high temperature. J Mater Res. 2011;22:2345-51. Epub 01/31.

15. Nakamoto Y, Sakata M, Sumiya H, Shimizu K, Irifune T, Matsuoka T, Ohishi Y. Note: High-pressure generation using nano-polycrystalline diamonds as anvil materials. Rev Sci Instrum. 2011;82:066104.

16. Guthrie M, Pruteanu CG, Donnelly M-E, Molaison JJ, dos Santos AM, Loveday JS, Boehler R, Tulk CA. Radiation attenuation by single-crystal diamond windows. J Appl Crystallogr. 2017;50:76-86.

17. Okuchi T, Sasaki S, Ohno Y, Abe J, Arima H, Osakabe T, Hattori T, Sano-Furukawa A, Komatsu K, Kagi H, Utsumi W, Harjo S, Ito T, Aizawa K. Neutron powder diffraction of smallvolume samples at high pressure using compact opposed-anvil cells and focused beam. Journal of Physics: Conference Series. 2012;377:012013.

18. Pawlus S, Klotz S, Paluch M. Effect of Compression on the Relationship between Viscosity and Dielectric Relaxation Time in Hydrogen-Bonded Primary Alcohols. Phys Rev Lett. 2013;110:173004. 
19. Takemura K, Sahu PC, Kunii Y, Toma Y. Versatile gas-loading system for diamondanvil cells. Rev Sci Instrum. 2001;72:3873-6.

20. Couzinet B, Dahan N, Hamel G, Chervin J-C. Optically monitored high-pressure gas loading apparatus for diamond anvil cells. High Press Res. 2003;23:409-15.

21. Hattori T, Sano-Furukawa A, Arima H, Komatsu K, Yamada A, Inamura Y, Nakatani T, Seto Y, Nagai T, Utsumi W, Iitaka T, Kagi H, Katayama Y, Inoue T, Otomo T, Suzuya K, Kamiyama T, Arai M, Yagi T. Design and performance of high-pressure PLANET beamline at pulsed neutron source at J-PARC. Nucl Instr, Meth Phys Res A. 2015;780:55-67.

22. Mao HK, Xu J, Bell PM. Calibration of the ruby pressure gauge to $800 \mathrm{kbar}$ under quasi-hydrostatic conditions. Journal of Geophysical Research: Solid Earth. 1986;91:4673-6.

23. Hemley RJ, Jephcoat AP, Mao HK, Zha CS, Finger LW, Cox DE. Static compression of H2O-ice to $128 \mathrm{GPa}$ (1.28 Mbar). Nature. 1987;330:737-40.

24. Wolanin E, Pruzan P, Chervin JC, Canny B, Gauthier M, Hausermann D, Hanfland M. Equation of state of ice VII up to 106 GPa. Phys Rev B. 1997;56:5781-5.

25. Somayazulu M, Shu JF, Zha CS, Goncharov AF, Tschauner O, Mao HK, Hemley RJ. In situ high-pressure x-ray diffraction study of $\mathrm{H}_{2} \mathrm{O}$ ice VII. J Chem Phys. 2008;128.

26. Yamashita K, Komatsu K, Klotz S, Fernández-Díaz MT, Fabelo O, Irifune T, Sugiyama K, Kawamata T, Kagi H. A nano-polycrystalline diamond anvil cell with bulk metallic glass cylinder for single-crystal neutron diffraction. High Press Res. 2019:1-8. 